\title{
Cognitive Assessment of Older People: Do Sensory Function and Frailty Matter?
}

\author{
Ruby Yu ${ }^{1,2, *(1)}$ and Jean Woo ${ }^{1,2}$ (1) \\ 1 Jockey Club Institute of Ageing, The Chinese University of Hong Kong, Hong Kong, China; \\ jeanwoowong@cuhk.edu.hk \\ 2 Department of Medicine and Therapeutics, Faculty of Medicine, The Chinese University of Hong Kong, \\ Hong Kong, China \\ * Correspondence: rubyyu@cuhk.edu.hk
}

Received: 1 February 2019; Accepted: 20 February 2019; Published: 24 February 2019

\begin{abstract}
Background: To examine the associations of visual and hearing functions, and frailty with subjective memory complaints (SMCs) in a community primary care pilot project of older people aged 60 years and over. Methods: The study was conducted in 24 community centers. A total of 1949 community-dwelling older people aged between 60-97 years were evaluated for which detailed information regarding socio-demographics, lifestyle, and clinical factors were documented at baseline and an average of 12 months later. SMCs were assessed using the 5-item Abbreviated Memory Inventory for the Chinese (AMIC). Visual and hearing functions were measured with two separate single questions. Frailty was assessed using a simple frailty question (FRAIL). Results: At baseline, $1685(74.6 \%)$ participants had reported at least 3 SMCs (AMIC score $\geq 3$ ). Of the 573 participants without / with 1-2 SMCs (AMIC score $=0-2$ ) at baseline, 75 had incomplete data regarding SMCs and 190 developed at least 3 SMCs after 12 months. After adjustments for age, sex, marital status, educational level, hypertension, and diabetes at baseline, poor vision (OR $2.295 \%$ CI 1.8-2.7), poor hearing (OR 2.2 95\% CI 1.8-2.8), and frailty (OR 4.6 95\% CI 3.1-6.7) at baseline were each significantly associated with an increased risk of at least $3 \mathrm{SMCs}$ at follow-up. After a further adjustment for baseline SMCs, the associations remained significant. Similar results were obtained when incident SMCs and improvement in subjective memory were used as the outcome variables; and Conclusions: In the care of older people, detection of sensory impairment and frailty through screening may allow formulation of strategies to prevent or delay the onset of cognitive decline.
\end{abstract}

Keywords: cognitive impairment; cognitive assessment; sensory function; vision; hearing; frailty; ageing

\section{Introduction}

Alzheimer's disease (AD) and other types of dementia affect older adults globally. People with mild cognitive impairment (MCI), especially MCI involving memory problems, have an increased risk of developing Alzheimer's disease (AD), with an annual progression rate of $10 \%-20 \%$ [1]. However, neuropathological changes of AD may occur many years before the onset of cognitive impairment or MCI [2-5]. Therefore, identifying early symptoms of cognitive decline can lead to the timely detection of diseases that lead to dementia, allowing for improved care and planning.

Subjective memory complaints (SMCs) have been suggested as a clinical indicator of cognitive decline and impairment before $\mathrm{AD}$ or other neurodegenerative processes in the course of the clinical manifestation of AD [6]. Short screening tests (e.g., Abbreviated Memory Inventory for Chinese, AMIC [7]) or simple questions (e.g., "Do you feel like your memory is becoming worse?" [6]) have been used to screen for SMCs in predicting cognitive outcomes. Longitudinal studies among older people 
without cognitive impairment identified SMCs as a predictor of cognitive decline and dementia [6,8-13]. A meta-analysis of 28 studies also demonstrated that older people with SMCs are more likely to develop dementia than those without SMCs [14] Nevertheless, SMCs may be particularly predictive for subsequent cognitive decline when they are accompanied by sensory impairment and/or frailty. A recent study suggests an association exists between sensory impairment and SMCs [15]. In addition, there is growing evidence to show the importance of sensory functions and frailty status for cognitive outcomes. Numerous longitudinal studies have demonstrated associations of visual and hearing impairments with cognitive decline [16-20], although conflicting findings have also been reported in another study [21]. Frailty, a state of decline in function reserves [22], has been associated with cognitive decline and subsequently major neurodegenerative disorder (dementia) [23-28]. Despite sensory function and frailty predicting cognitive decline, less attention has been paid to the inclusion of these conditions in cognitive assessment.

Therefore, we examined the associations of visual and hearing function and frailty with SMCs in a community primary care pilot project of older people aged 60 years and over where SMCs was assessed over a duration of 12 months. If visual and hearing functions and frailty are associated with SMCs/predictive of the development of SMCs, the implication is that, these conditions should form an important part of cognitive assessment.

\section{Materials and Methods}

\subsection{Setting and Participants}

A community pilot project on a model of primary care of older people was started in 2016, based in 24 community centers in all three regions of Hong Kong (Hong Kong Island, Kowloon, and the New Territories). The primary aim was to improve community care of older people with hypertension and diabetes. Fifty members of each center aged 60 years and over were invited to participate. Priority was given to those with known hypertension and diabetes, and those judged by the center members to benefit from community group activities. The study was approved by the Survey and Behavioral Ethics Committee of the Chinese University of Hong Kong (No. 126-16). Informed consent was obtained from all participants.

\subsection{Data Collection}

A brief multi-domain geriatric assessment was used to screen for geriatric conditions. It was self-administered electronically using an e-tablet. Screening results were uploaded to a secure server for subsequent analyses. Positive responses were flagged and a report was generated to project team members, in order to identify issues to be followed-up with shared decision making on what pathways (i.e., interventions and courses of action) to pursue. Resources to guide interventions and actions for each domain were compiled in conjunction with health professionals, using a stepped care approach of self-management, brief interventions and/or group-based support activities, and secondary care services. The brief geriatric assessment was repeated approximately 12 months later.

\subsection{The Brief Geriatric Assessment}

\subsubsection{Subjective Memory Complaints}

The 5-item AMIC was used for screening for SMCs. AMIC is an abbreviated version of the original 27-item Memory Inventory for the Chinese (validated for the diagnosis of MCI, with a sensitivity of $54.6 \%-65.3 \%$ and specificity of $57.4 \%$ ). There are five items: "Do you always forget where you put your stuff?", "Do you feel that your memory is worse than your peers?", "Do you always forget what you want to say during a conversation?", "Do you always fail to find the appropriate word to express your idea during a conversation?", and "Do you forget your acquaintances' names when you meet 
them?". AMIC scores range from 0-5 (1 point for each item; 0-best to 5-worse). An AMIC score $\geq 3$ is predictive of MCI [6].

\subsubsection{Sensory Function}

Visual and hearing functions were measured with two separate single questions, "Do you have any difficulty seeing things?" and "Do you have any difficulty hearing?", respectively. The response categories were "very good", "good", "fair", "not too well", "poor", and "very poor" which were collapsed to form a binary attribute for regression analysis (i.e., "very good" and "good" = "robust"; "fair", "not too well", "poor", and "very poor" = "poor").

\subsubsection{Frailty}

Frailty was assessed using a simple frailty questionnaire (FRAIL). There are five items of the FRAIL scale: fatigue, resistance, ambulation, illnesses, and loss of weight. The FRAIL scores range from $0-5$, with $0-1$ point for each item and a score of 0 represents robust, $1-2$ as pre-frail, and 3-5 as frail $[29,30]$.

\subsubsection{Other Geriatric Symptoms}

Other measures included a single question for chewing difficulties, a simple questionnaire to rapidly diagnose sarcopenia based on Strength, Assistance in walking, Rise from a chair, Climb stairs, and Falls (SARC-F), a single question for self-rated health, "How would you rate your general health?", three questions for subjective well-being (life satisfaction, feelings of happiness, and sense of purpose and meaning in life), a single question for incontinence, "Do you have problems with incontinence?", five items for Instrumental Activity Daily Living (IADL) impairments, a single question for medication, "How many types of medication prescribed by the doctor are you taking?", and a single question for finance issue, "Do you have enough money for day to day use?". However, these measures were not included in the analysis.

\subsection{Statistical Analysis}

Data were summarized as means (standard deviations) for continuous variables and as percentages for categorical data. Participant characteristics were compared across cognitive status at baseline based on the AMIC score (No SMC with an AMIC score = 0; 1-2 SMCs with an AMIC score $=1-2$, at least 3 SMCs with an AMIC score $\geq 3$ ) using analysis of variance (ANOVA) for continuous variables and chi-square tests for categorical variables. Logistic regression models were used to estimate the longitudinal associations of visual function (robust, poor), hearing function (robust, poor), and frailty status (robust, pre-frail, and frail) at baseline and SMCs after an average of 12 months. Progressive models were used as follows: model 1, no adjustment; model 2, adjustment for age and sex; model 3, further adjustments for marital status (not married, married) and educational level (no education/primary, secondary/tertiary); and model 4 further adjustments for hypertension (no, yes) and diabetes (no, yes). An additional model (Model 5) was performed with a further adjustment for baseline SMCs. Sensitivity analyses were also performed to see how redefining the outcome variable (using incident SMCs and improvement in subjective memory) changes the observed effects of visual and hearing functions, and frailty on SMCs. Analyses were carried out using the Window-based SPSS Statistical Package v24.0 (IBM Corp. Released 2013. Armonk, NY, USA), and $p$ values less than 0.05 were considered statistically significant.

\section{Results}

\subsection{Baseline Characteristics of the Study Population}

At baseline, 2259 Chinese people aged between 60-97 years completed the brief geriatric assessment. The mean age of the participants was 76.1 years, $76.9 \%$ were women, $47 \%$ were married, 
$72 \%$ received at least primary education, and $34.9 \%$ were living alone. In total, $74.6 \%$ had at least 3 SMCs, $57.8 \%$ and $44.3 \%$ reported poor vision and poor hearing, respectively and additionally, $64.2 \%$ had a FRAIL score $\geq 1$ (i.e., classified as pre-frail and frail) (Table 1).

Table 1. Baseline characteristics of the study population $(n=2259)$.

\begin{tabular}{|c|c|}
\hline Variable & Mean $\pm \mathrm{SD} / n(\%)$ \\
\hline Age (years), mean $\pm \mathrm{SD}$ (range) & $76.1 \pm 7.4(60-97)$ \\
\hline \multicolumn{2}{|l|}{ Age, $n(\%)$} \\
\hline $60-69$ years & $503(22.3)$ \\
\hline $70-79$ years & $972(43.0)$ \\
\hline $80+$ years & $784(34.7)$ \\
\hline \multicolumn{2}{|l|}{ Sex, $n(\%)$} \\
\hline Men & $521(23.1)$ \\
\hline Women & $1738(76.9)$ \\
\hline \multicolumn{2}{|l|}{ Marital status, $n(\%)$} \\
\hline Single & $103(4.6)$ \\
\hline Married & $1061(47.0)$ \\
\hline Widowed & $958(42.4)$ \\
\hline Divorced/separated & $137(6.1)$ \\
\hline \multicolumn{2}{|l|}{ Educational level, $n(\%)$ * } \\
\hline No education & $633(28.0)$ \\
\hline Primary & $1002(44.4)$ \\
\hline Secondary & $516(22.9)$ \\
\hline Tertiary & $107(4.7)$ \\
\hline \multicolumn{2}{|l|}{ Living arrangement, $n(\%) *$} \\
\hline Living alone & $788(34.9)$ \\
\hline Living with spouse & $631(27.9)$ \\
\hline Living with children & $482(21.3)$ \\
\hline Living with spouse and children & $283(12.5)$ \\
\hline Living with others (e.g., domestic helper) & $74(3.3)$ \\
\hline \multicolumn{2}{|l|}{ Self-reported hypertension, $n(\%)$} \\
\hline No & $782(34.6)$ \\
\hline Yes & $1477(65.4)$ \\
\hline \multicolumn{2}{|l|}{ Self-reported diabetes, $n(\%)$} \\
\hline No & $1628(72.1)$ \\
\hline Yes & $631(27.9)$ \\
\hline \multicolumn{2}{|l|}{ SMCs, $n(\%) *$} \\
\hline No SMC, AMIC score $=0$ & $137(6.1)$ \\
\hline 1-2 SMCs, AMIC score $=1-2$ & $436(19.3)$ \\
\hline At least 3 SMCs, AMIC score $\geq 3$ & $1685(74.6)$ \\
\hline \multicolumn{2}{|l|}{ Vision, $n(\%)$} \\
\hline Very good & $346(15.3)$ \\
\hline Good & $607(26.9)$ \\
\hline Fair & $777(34.4)$ \\
\hline Not too well & $391(17.3)$ \\
\hline Poor & $127(5.6)$ \\
\hline Very poor & $11(0.5)$ \\
\hline \multicolumn{2}{|l|}{ Hearing, $n(\%)$} \\
\hline Very good & $599(26.5)$ \\
\hline Good & $660(29.2)$ \\
\hline Fair & $607(26.9)$ \\
\hline Not too well & $302(13.4)$ \\
\hline Poor & $83(3.7)$ \\
\hline Very poor & $8(0.4)$ \\
\hline \multicolumn{2}{|l|}{ Frailty, $n(\%) *$} \\
\hline Robust, FRAIL score $=0$ & $809(35.8)$ \\
\hline Pre-frail, FRAIL score $=1-2$ & $1040(46.1)$ \\
\hline Frail, FRAIL score $\geq 3$ & $409(18.1)$ \\
\hline
\end{tabular}

Abbreviation: SMCs, Subjective Memory Complaints; AMIC, Abbreviated Memory Inventory for the Chinese. * Missing value: Educational level $(n=1)$; living arrangement $(n=1)$; SMCs $(n=1)$; frailty $(n=1)$. Percentages may not add up to $100 \%$ due to rounding. 


\subsection{Factors Associated with SMCs}

As expected, participants who had at least 3 SMCs were older, predominantly women $(81.1 \%)$, and more likely to be living alone (36.6\%), and with higher proportions of poor vision $(64.0 \%)$, poor hearing $(49.6 \%)$, and frailty $(71.7 \%)$. They also had a lower proportion of being married $(45.4 \%)$ and a lower level of education (secondary education or above, 23.9\%) (Table 2).

Table 2. Baseline characteristics of the study population by cognitive status $\left(n=2258^{*}\right)$.

\begin{tabular}{ccccc}
\hline Variable & $\begin{array}{c}\text { No SMC } \\
\text { AMIC }=\mathbf{0} \\
(\boldsymbol{n}=\mathbf{1 3 7 )}\end{array}$ & $\begin{array}{c}\text { 1-2 SMCs } \\
\text { AMIC }=\mathbf{1 - 2} \\
(\boldsymbol{n}=\mathbf{4 3 6})\end{array}$ & $\begin{array}{c}\text { At Least 3 SMCs } \\
\text { AMIC } \geq \mathbf{3} \\
(\boldsymbol{n}=\mathbf{1 6 8 5})\end{array}$ & $\boldsymbol{p}$ \\
\hline Age, years & $73.8 \pm 7.4$ & $75.6 \pm 7.8$ & $76.4 \pm 7.3$ & $<0.001$ \\
Women, \% & $78(56.9)$ & $293(67.2)$ & $1367(81.1)$ & $<0.001$ \\
Married, \% & $70(51.1)$ & $225(51.6)$ & $765(45.4)$ & 0.042 \\
Secondary education or above, \% & $54(39.4)$ & $166(38.2)$ & $403(23.9)$ & $<0.001$ \\
Living alone, \% & $45(33.1)$ & $127(29.1)$ & $616(36.6)$ & 0.013 \\
Hypertension, \% & $95(69.3)$ & $277(63.5)$ & $1105(65.6)$ & 0.441 \\
Diabetes, \% & $44(32.1)$ & $116(26.6)$ & $471(28.0)$ & 0.456 \\
Poor vision, \% & $43(31.4)$ & $184(42.2)$ & $1079(64.0)$ & $<0.001$ \\
Poor hearing, \% & $26(19.0)$ & $138(31.7)$ & $836(49.6)$ & $<0.001$ \\
Pre-frailty and frailty, \% & $46(33.6)$ & $204(46.9)$ & $1198(71.1)$ & $<0.001$ \\
\hline Abbreviation: AMIC, Abbreviated Memory Inventory for the Chinese * Missing data: $n=1$. &
\end{tabular}

\subsection{Longitudinal Associations of Poor Vision, Poor Hearing, and Frailty with SMCs}

An average of 12 months after baseline, 1949 participants returned with 1947 completed the 5-item AMIC and 1418 (72.8\%) participants had at least 3 SMCs. Of the 498 participants without / with 1-2 SMCs at baseline that returned at follow-up, 190 (38.2\%) had developed at least 3 SMCs at follow-up (Figure 1).

Poor vision (OR 2.2 95\% CI 1.8-2.7), poor hearing (OR 2.2 95\% CI 1.8-2.8), and frailty (OR 4.6 95\% CI 3.1-6.7) at baseline were each significantly associated with an increased risk of SMCs (AMIC score $\geq 3$ ) at follow-up, after adjustment for age, sex, marital status, educational level, hypertension, and diabetes at baseline. After a further adjustment for baseline SMCs, the associations remained significant (Table 3).

Sensitivity analyses were performed using incident SMCs and improvement in subjective memory as the outcome variables. Of the 498 participants without / with 1-2 SMCs at baseline, poor vision (OR 1.6, 95\% CI 1.1-2.3), poor hearing (OR 1.9, 95\% CI 1.2-2.8), and frailty (OR 3.1, 95\% CI 1.5-6.8) were each significantly associated with an increased risk of incidence of SMCs (AMIC score $\geq 3$ ), independent of age, sex, marital status, educational level, hypertension, and diabetes at baseline (Table 4). Of the 1449 participants with at least $3 \mathrm{SMCs}$ at baseline that returned at follow-up, robust vision (OR 1.6, 95\% CI 1.2-2.2), robust hearing (OR 1.5, 95\% CI 1.1-2.1), robust (OR 2.6, 95\% CI 1.6-4.2) and pre-frailty (OR 2.0, 95\% CI 1.2-3.1) status were each significantly associated with an increased likelihood of improvement in subjective memory, independent of age, sex, marital status, educational level, hypertension, and diabetes at baseline (Table 5). 


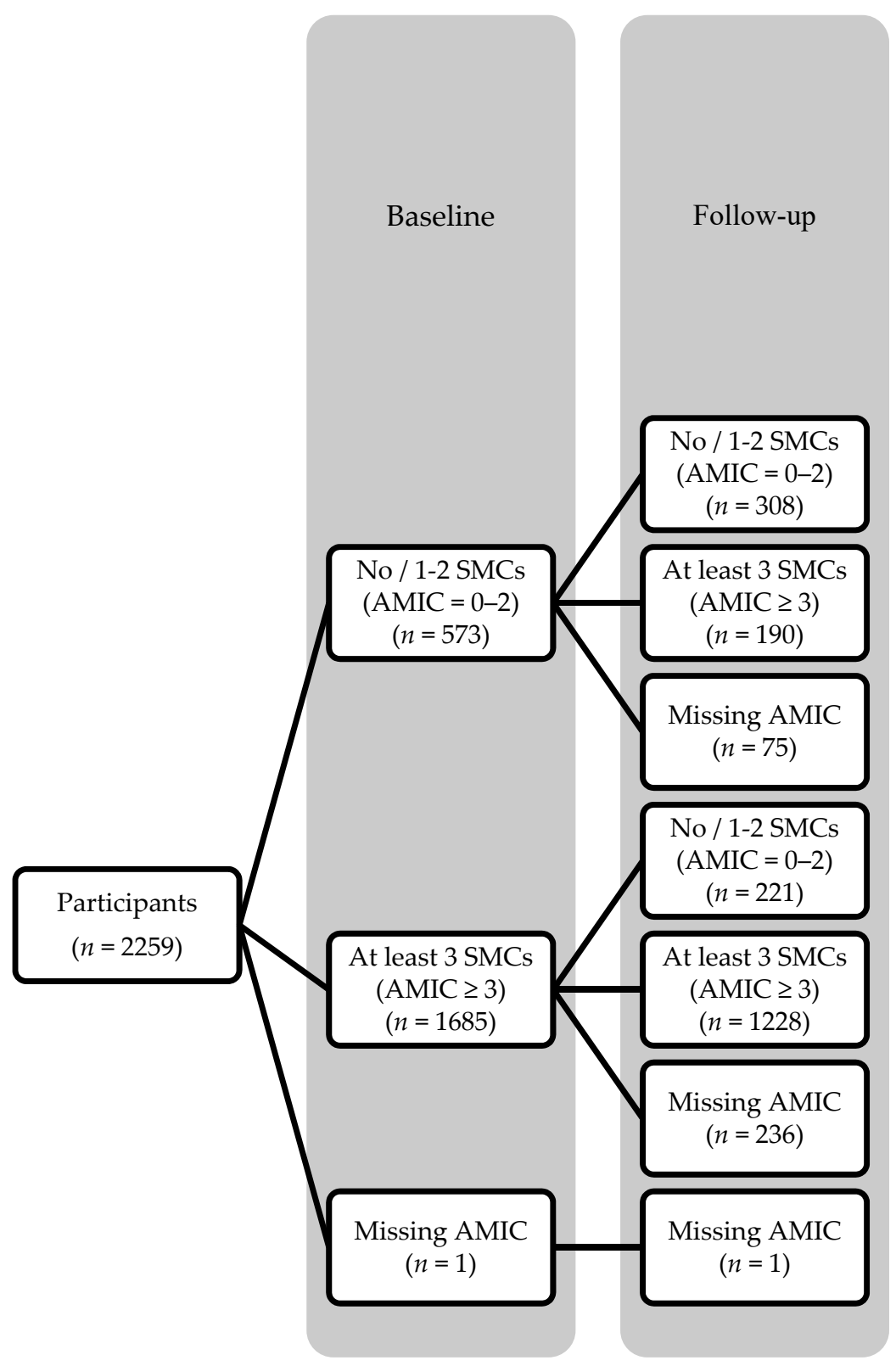

Figure 1. Flow chart of participants.

Table 3. Associations of sensory impairment and frailty with subjective memory complaints (SMCs) after 12 months $(n=1947)$.

\begin{tabular}{|c|c|c|c|c|c|c|c|c|c|c|c|}
\hline \multirow{2}{*}{ Variables } & \multirow{2}{*}{$n(\%)$} & \multicolumn{2}{|c|}{ Model 1} & \multicolumn{2}{|c|}{ Model 2} & \multicolumn{2}{|c|}{ Model 3} & \multicolumn{2}{|c|}{ Model 4} & \multicolumn{2}{|c|}{ Model 5} \\
\hline & & OR & $95 \% \mathrm{CI}$ & OR & $95 \%$ CI & OR & $95 \% \mathrm{CI}$ & OR & $95 \%$ CI & OR & $95 \%$ CI \\
\hline \multicolumn{12}{|l|}{ Vision } \\
\hline Robust & $816(41.9)$ & Reference & & Reference & & Reference & & Reference & & Reference & \\
\hline Poor & $1131(58.1)$ & 2.3 & $1.9-2.8$ & 2.3 & $1.8-2.8$ & 2.2 & $1.8-2.8$ & 2.2 & $1.8-2.7$ & 1.6 & $1.3-2.0$ \\
\hline \multicolumn{12}{|l|}{ Hearing } \\
\hline Robust & 1089 (55.9) & Reference & & Reference & & Reference & & Reference & & Reference & \\
\hline Poor & $858(44.1)$ & 2.2 & $1.7-2.7$ & 2.2 & $1.8-2.7$ & 2.2 & $1.8-2.8$ & 2.2 & $1.8-2.8$ & 1.7 & $1.3-2.1$ \\
\hline \multicolumn{12}{|l|}{ Frailty } \\
\hline Robust & 713 (36.6) & Reference & & Reference & & Reference & & Reference & & Reference & \\
\hline Pre-frail & $902(46.3)$ & 1.9 & $1.6-2.4$ & 1.9 & $1.5-2.3$ & 1.9 & $1.5-2.3$ & 1.9 & $1.5-2.3$ & 1.3 & $1.0-1.7$ \\
\hline Frail & 332 (17.1) & 4.8 & $3.3-6.9$ & 4.5 & $3.1-6.6$ & 4.6 & $3.1-6.7$ & 4.6 & $3.1-6.7$ & 2.7 & $1.8-4.1$ \\
\hline
\end{tabular}

Model 1: crude. Model 2: age and sex. Model 3: age, sex, marital status, and educational level. Model 4: age, sex, marital status, educational level, hypertension, and diabetes. Model 5: age, sex, marital status, educational level, hypertension, diabetes, and baseline cognitive status. 
Table 4. Associations of sensory impairment and frailty with improvement in incident SMCs after 12 months $(n=498)$.

\begin{tabular}{|c|c|c|c|c|c|c|c|c|c|}
\hline \multirow[b]{2}{*}{ Variables } & \multirow{2}{*}{$n(\%)$} & \multicolumn{2}{|c|}{ Model 1} & \multicolumn{2}{|c|}{ Model 2} & \multicolumn{2}{|c|}{ Model 3} & \multicolumn{2}{|c|}{ Model 4} \\
\hline & & OR & $95 \% \mathrm{CI}$ & OR & $95 \% \mathrm{CI}$ & OR & $95 \%$ CI & OR & $95 \% \mathrm{CI}$ \\
\hline \multicolumn{10}{|l|}{ Vision } \\
\hline Robust & $301(60.4)$ & Reference & & Reference & & Reference & & Reference & \\
\hline Poor & $197(39.6)$ & 1.6 & $1.1-2.4$ & 1.6 & $1.1-2.3$ & 1.6 & $1.1-2.3$ & 1.6 & $1.1-2.3$ \\
\hline \multicolumn{10}{|l|}{ Hearing } \\
\hline Robust & 356 (71.5) & Reference & & Reference & & Reference & & Reference & \\
\hline Poor & $142(28.5)$ & 1.8 & $1.2-2.7$ & 1.8 & $1.2-2.8$ & 1.9 & $1.2-2.8$ & 1.9 & $1.2-2.8$ \\
\hline \multicolumn{10}{|l|}{ Frailty } \\
\hline Robust & $279(56.0)$ & Reference & & Reference & & Reference & & Reference & \\
\hline Pre-frail & 185 (37.1) & 1.5 & $1.0-2.1$ & 1.4 & $1.0-2.1$ & 1.4 & $1.0-2.1$ & 1.4 & $1.0-2.1$ \\
\hline Frail & $34(6.8)$ & 3.3 & $1.6-6.9$ & 3.1 & $1.5-6.7$ & 3.3 & $1.6-7.1$ & 3.1 & $1.5-6.8$ \\
\hline
\end{tabular}

Model 1: crude. Model 2: age and sex. Model 3: age, sex, marital status, and educational level. Model 4: age, sex, marital status, educational level, hypertension, and diabetes.

Table 5. Associations of sensory impairment and frailty with improvement in subjective memory after 12 months $(n=1449)$.

\begin{tabular}{|c|c|c|c|c|c|c|c|c|c|}
\hline \multirow{2}{*}{ Variables } & \multirow{2}{*}{$n(\%)$} & \multicolumn{2}{|c|}{ Model 1} & \multicolumn{2}{|c|}{ Model 2} & \multicolumn{2}{|c|}{ Model 3} & \multicolumn{2}{|c|}{ Model 4} \\
\hline & & OR & $95 \%$ CI & OR & $95 \% \mathrm{CI}$ & OR & $95 \%$ CI & OR & $95 \% \mathrm{CI}$ \\
\hline \multicolumn{10}{|l|}{ Vision } \\
\hline Poor & $934(64.5)$ & Reference & & Reference & & Reference & & Reference & \\
\hline Robust & $515(35.5)$ & 1.6 & $1.2-2.2$ & 1.6 & $1.2-2.2$ & 1.6 & $1.2-2.2$ & 1.6 & $1.2-2.2$ \\
\hline \multicolumn{10}{|l|}{ Hearing } \\
\hline Poor & $716(49.4)$ & Reference & & Reference & & Reference & & Reference & \\
\hline Robust & $733(50.6)$ & 1.5 & $1.1-2.0$ & 1.5 & $1.1-2.1$ & 1.5 & $1.1-2.1$ & 1.5 & $1.1-2.1$ \\
\hline \multicolumn{10}{|l|}{ Frailty } \\
\hline Frail & $298(20.6)$ & Reference & & Reference & & Reference & & Reference & \\
\hline Pre-frail & 717 (49.5) & 2.0 & $1.3-3.2$ & 2.0 & $1.2-3.1$ & 2.0 & $1.2-3.1$ & 2.0 & $1.2-3.1$ \\
\hline Robust & $434(30.0)$ & 2.7 & $1.7-4.3$ & 2.6 & $1.6-4.2$ & 2.5 & $1.6-4.1$ & 2.6 & $1.6-4.2$ \\
\hline
\end{tabular}

Model 1: crude. Model 2: age and sex. Model 3: age, sex, marital status, and educational level. Model 4: age, sex, marital status, educational level, hypertension, and diabetes.

\section{Discussion}

In this community-based study, the proportion of people with SMCs was high. Moreover, participants with poor vision, poor hearing, or frailty at baseline were associated with an increased risk of SMCs after an average of 12 months, independent of age, sex, marital status, educational level, hypertension, diabetes at baseline. These findings reinforce the importance of assessing sensory function and frailty status in cognitive assessment of older people.

Our findings indicate that visual and hearing functions were significant and independent predictors of SMCs among older people aged 60 and over. This finding is in concordance with the observation from a national survey in the United Kingdom showing a significant proportion of visual impairment (approximately one-third) detected in a sample of people with dementia [31]. A recent pooled analysis of data from eleven studies reported that individuals with either peripheral or central hearing dysfunction had a higher risk of having cognitive impairment at follow-up [19]. Hence, our results add further support to the possibility that sensory impairment may be an early symptom of an underlying neurodegenerative process (such as degeneration of central nervous structures), before the clinical manifestation of cognitive impairment. Poor visual and hearing functions may also contribute to reduced physical and mental activities (indicating a prolonged lack of adequate sensory input), which in turn predisposes to cognitive deterioration possibility due to neuronal atrophy [32]. Nevertheless, there may be other reasons for an older person with sensory impairment that leads to cognitive decline. For example, older people who cannot see well or hear well may become depressed, which increases the risk of cognitive deterioration. Although we did not collect information regarding depressive symptoms, analyses of our data found that poor vision and poor hearing were significantly associated with low subjective well-being (in terms of life satisfaction, feelings of happiness, and sense 
of purpose and meaning in life), which was positively associated with SMCs (data not shown). Our study could have potential public health implications, as it suggests that identifying and targeting sensory problems in older people could be a potentially useful strategy for preventing cognitive decline.

Our finding also demonstrates that frailty was a significant and independent predictor of SMCs. This finding extends the findings of previous studies that frailty predicts cognitive decline and incident dementia [23-28], and thus adds support to the possibility that frailty may predispose to cognitive decline and subsequently major neurodegenerative disorder (dementia). Although the underlying mechanisms are still unclear, a chronic inflammatory state has been postulated to be an underlying etiology of frailty and cognitive impairment [33]. An alternative explanation is that frailty may be causally associated with reduced physical and mental activities [34], which are related to an increased risk of cognitive decline [35]. While frailty predicts cognitive decline, some studies have suggested that cognitive impairment predicts frailty [36]. Furthermore, there is increasing evidence that, even with normal ageing, both frailty and cognitive decline often coexist [37], and the occurrence of both conditions has been associated with higher risks of adverse health outcomes [38]. Therefore, among older people, frailty may indicate the presence of cognitive decline, and should be part of cognitive assessment for older people in the community.

The significant longitudinal associations of poor vision, poor hearing, and frailty with SMCs provide evidence of their suitability for applications in the community settings. The WHO guidelines on community-level interventions to manage declines in intrinsic capacity (Integrated Care For Older People, ICOPE) also recommend assessing indicators of decline in physical and mental capacities, using a people-centered approach [39]. Therefore, simple screening questions (e.g., the presence of visual and hearing impairments) and frailty assessment (e.g., the FRAIL scale) can be adopted in community settings. Positive responses to the questions/assessment should trigger further assessments (e.g., visual acuity, hearing capacity, activity of daily living, etc.) and management by health support network in the community.

Our study should be viewed within the context of its limitations. First, the AMIC was used to screen for SMCs and as a proxy for measuring cognitive decline. Due to the lack of formal testing, there remains some uncertainty as to whether some of the participants classified as having SMCs might actually have had MCI. Second, the specificity of the AMIC was relatively low, as memory complaints were frequently reported among those with normal cognition [6]. Third, standardized tests of vision and hearing were not performed, which may introduce information bias. Nevertheless, the AMIC score and the simple questions used to screen for visual and hearing problems in this study help trigger further in-depth assessments, which may be used as the first step in a stepped-care approach to detect cognitive and sensory impairments in the community, allowing targeted intervention to potentially retard cognitive decline. Fourth, the follow-up period may not be long enough to capture the change in cognitive function. Fifth, data on unmeasured factors, such as comorbid depression which is an important risk factor for cognitive impairment, were not available and could not be controlled for. Lastly, although the findings of the present study are based on community-based sample obtained in 24 community centers in all three regions of Hong Kong, they may not be generalizable to institutionalized populations.

\section{Conclusions}

The findings of this study support the proposal that sensory function and frailty should be assessed together with cognitive assessment, which may enhance the prediction for cognitive decline and allow formulation of strategies to prevent or delay the onset of cognitive decline.

Author Contributions: Conceptualization, R.Y. and J.W.; methodology, R.Y. and J.W.; analysis, R.Y.; writing—original draft preparation, R.Y.; writing—review and editing, R.Y. and J.W.

Funding: This research was funded by the Hong Kong Jockey Club Charities Trust, reference number 2016/0073-002. 
Acknowledgments: We thank the team members (Lok-yan Tam, Clara Cheng, Sara Kong, Cecilia Tong, members of the Stanley Ho Big Data Decision Analytics Research Centre, and members of community centers) for the collection, collation, validation and management of the data used in this article. We thank the participants of the Jockey Club Community e-Health Care Project.

Conflicts of Interest: The authors declare no conflict of interest. The funders had no role in the design of the study; in the collection, analyses, or interpretation of data; in the writing of the manuscript, or in the decision to publish the results.

\section{References}

1. Winblad, B.; Palmer, K.; Kivipelto, M.; Jelic, V.; Fratiglioni, L.; Wahlund, L.O.; Nordberg, A.; Backman, L.; Albert, M.; Almkvist, O.; et al. Mild cognitive impairment-beyond controversies, towards a consensus: Report of the International Working Group on Mild Cognitive Impairment. J. Intern. Med. 2004, 256, 240-246. [CrossRef] [PubMed]

2. Launer, L.J. The epidemiologic study of dementia: A life-long quest? Neurobiol. Ag. 2005, 26, 335-340. [CrossRef] [PubMed]

3. Storandt, M.; Grant, E.A.; Miller, J.P.; Morris, J.C. Longitudinal course and neuropathologic outcomes in original vs revised MCI and in pre-MCI. Neurology 2006, 67, 467-473. [CrossRef] [PubMed]

4. Caselli, R.J.; Chen, K.; Lee, W.; Alexander, G.E.; Reiman, E.M. Correlating cerebral hypometabolism with future memory decline in subsequent converters to amnestic pre-mild cognitive impairment. Arch. Neurol. 2008, 65, 1231-1236. [CrossRef] [PubMed]

5. Singh-Manoux, A.; Kivimaki, M.; Glymour, M.M.; Elbaz, A.; Berr, C.; Ebmeier, K.P.; Ferrie, J.E.; Dugravot, A. Timing of onset of cognitive decline: Results from Whitehall II prospective cohort study. BMJ 2012, 344. [CrossRef] [PubMed]

6. Jessen, F.; Wiese, B.; Bachmann, C.; Eifflaender-Gorfer, S.; Haller, F.; Kolsch, H.; Luck, T.; Mosch, E.; van den Bussche, H.; Wagner, M.; et al. Prediction of dementia by subjective memory impairment: Effects of severity and temporal association with cognitive impairment. Arch. Gen. Psychiatry 2010, 67, 414-422. [CrossRef] [PubMed]

7. Lam, L.C.; Lui, V.W.; Tam, C.W.; Chiu, H.F. Subjective memory complaints in Chinese subjects with mild cognitive impairment and early Alzheimer's disease. Int. J. Geriatr. Psychiatry 2005, 20, 876-882. [CrossRef] [PubMed]

8. Geerlings, M.I.; Jonker, C.; Bouter, L.M.; Ader, H.J.; Schmand, B. Association between memory complaints and incident Alzheimer's disease in elderly people with normal baseline cognition. Am. J. Psychiatry 1999, 156, 531-537. [PubMed]

9. Jessen, F.; Wolfsgruber, S.; Wiese, B.; Bickel, H.; Mosch, E.; Kaduszkiewicz, H.; Pentzek, M.; Riedel-Heller, S.G.; Luck, T.; Fuchs, A.; et al. AD dementia risk in late MCI, in early MCI, and in subjective memory impairment. Alzheimers Dement. 2014, 10, 76-83. [CrossRef] [PubMed]

10. Kaup, A.R.; Nettiksimmons, J.; LeBlanc, E.S.; Yaffe, K. Memory complaints and risk of cognitive impairment after nearly 2 decades among older women. Neurology 2015, 85, 1852-1858. [CrossRef] [PubMed]

11. Luck, T.; Luppa, M.; Matschinger, H.; Jessen, F.; Angermeyer, M.C.; Riedel-Heller, S.G. Incident subjective memory complaints and the risk of subsequent dementia. Acta Psychiatr. Scand. 2015, 131, 290-296. [CrossRef] [PubMed]

12. Ronnlund, M.; Sundstrom, A.; Adolfsson, R.; Nilsson, L.G. Subjective memory impairment in older adults predicts future dementia independent of baseline memory performance: Evidence from the Betula prospective cohort study. Alzheimers Dement. 2015, 11, 1385-1392. [CrossRef] [PubMed]

13. Tsutsumimoto, K.; Makizako, H.; Doi, T.; Hotta, R.; Nakakubo, S.; Makino, K.; Shimada, H.; Suzuki, T. Subjective Memory Complaints are Associated with Incident Dementia in Cognitively Intact Older People, but Not in Those with Cognitive Impairment: A 24-Month Prospective Cohort Study. Am. J. Geriat. Psychiatry 2017, 25, 607-616. [CrossRef] [PubMed]

14. Mitchell, A.J.; Beaumont, H.; Ferguson, D.; Yadegarfar, M.; Stubbs, B. Risk of dementia and mild cognitive impairment in older people with subjective memory complaints: Meta-analysis. Acta Psychiatr. Scand. 2014, 130, 439-451. [CrossRef] [PubMed] 
15. Pedro, M.C.; Mercedes, M.P.; Ramon, L.H.; Borja, M.R. Subjective memory complaints in elderly: Relationship with health status, multimorbidity, medications, and use of services in a population-based study. Int. Psychogeriatr. 2016, 28, 1903-1916. [CrossRef] [PubMed]

16. Lin, M.Y.; Gutierrez, P.R.; Stone, K.L.; Yaffe, K.; Ensrud, K.E.; Fink, H.A.; Sarkisian, C.A.; Coleman, A.L.; Mangione, C.M. Study of Osteoporotic Fractures Research Group. Vision impairment and combined vision and hearing impairment predict cognitive and functional decline in older women. J. Am. Geriatr. Soc. 2004, 52, 1996-2002. [CrossRef] [PubMed]

17. Ong, S.Y.; Cheung, C.Y.; Li, X.; Lamoureux, E.L.; Ikram, M.K.; Ding, J.; Cheng, C.Y.; Haaland, B.A.; Saw, S.M.; Venketasubramanian, N.; et al. Visual impairment, age-related eye diseases, and cognitive function: The Singapore Malay Eye study. Arch. Ophthalmol. 2012, 130, 895-900. [CrossRef] [PubMed]

18. Hewitt, D. Age-Related Hearing Loss and Cognitive Decline: You Haven't Heard the Half of It. Front. Ag. Neurosci. 2017, 9, 112. [CrossRef] [PubMed]

19. Yuan, J.; Sun, Y.; Sang, S.; Pham, J.H.; Kong, W.J. The risk of cognitive impairment associated with hearing function in older adults: A pooled analysis of data from eleven studies. Sci. Rep. 2018, 8, 2137. [CrossRef] [PubMed]

20. Maharani, A.; Dawes, P.; Nazroo, J.; Tampubolon, G.; Pendleton, N. Visual and hearing impairments are associated with cognitive decline in older people. Age Ageing 2018, 47, 575-581. [CrossRef] [PubMed]

21. Reyes-Ortiz, C.A.; Kuo, Y.F.; DiNuzzo, A.R.; Ray, L.A.; Raji, M.A.; Markides, K.S. Near vision impairment predicts cognitive decline: Data from the Hispanic Established Populations for Epidemiologic Studies of the Elderly. J. Am. Geriatr. Soc. 2005, 53, 681-686. [CrossRef] [PubMed]

22. Fried, L.P.; Tangen, C.M.; Walston, J.; Newman, A.B.; Hirsch, C.; Gottdiener, J.; Seeman, T.; Tracy, R.; Kop, W.J.; Burke, G.; et al. Frailty in older adults: Evidence for a phenotype. J. Gerontol. Ser. Biol. Sci. Med. Sci. 2001, 56, 146-156. [CrossRef]

23. Samper-Ternent, R.; Al Snih, S.; Raji, M.A.; Markides, K.S.; Ottenbacher, K.J. Relationship between frailty and cognitive decline in older Mexican Americans. J. Am. Geriatr. Soc. 2008, 56, 1845-1852. [CrossRef] [PubMed]

24. Boyle, P.A.; Buchman, A.S.; Wilson, R.S.; Leurgans, S.E.; Bennett, D.A. Physical Frailty Is Associated with Incident Mild Cognitive Impairment in Community-Based Older Persons. J. Am. Geriatr. Soc. 2010, 8, 248-255. [CrossRef] [PubMed]

25. Mitnitski, A.; Fallah, N.; Rockwood, M.R.; Rockwood, K. Transitions in cognitive status in relation to frailty in older adults: A comparison of three frailty measures. J. Nutr. Health Aging 2011, 15, 863-867. [CrossRef] [PubMed]

26. Solfrizzi, V.; Scafato, E.; Frisardi, V.; Seripa, D.; Logroscino, G.; Maggi, S.; Imbimbo, B.P.; Galluzzo, L.; Baldereschi, M.; Gandin, C.; et al. Frailty syndrome and the risk of vascular dementia: The Italian Longitudinal Study on Aging. Alzheimers Dement. 2013, 9, 113-122. [CrossRef] [PubMed]

27. Feng, L.; Nyunt, M.S.; Gao, Q.; Lee, T.S.; Tsoi, T.; Chong, M.S.; Lim, W.S.; Collinson, S.; Yap, P.; Yap, K.B.; et al. Physical Frailty, Cognitive Impairment, and the Risk of Neurocognitive Disorder in the Singapore Longitudinal Ageing Studies. J. Gerontol. Ser. Biol. Sci. Med. Sci. 2017, 72, 369-375. [CrossRef] [PubMed]

28. Tian, Q.; An, Y.; Resnick, S.M.; Studenski, S. The relative temporal sequence of decline in mobility and cognition among initially unimpaired older adults: Results from the Baltimore Longitudinal Study of Aging. Age Ageing 2017, 46, 445-451. [CrossRef] [PubMed]

29. Morley, J.E.; Malmstrom, T.K.; Miller, D.K. A simple frailty questionnaire (FRAIL) predicts outcomes in middle aged African Americans. J. Nutr. Health Aging 2012, 16, 601-608. [CrossRef] [PubMed]

30. Woo, J.; Yu, R.; Wong, M.; Yeung, F.; Lum, C. Frailty Screening in the Community Using the FRAIL Scale. J. Am. Med. Dir. Assoc. 2015, 16, 412-419. [CrossRef] [PubMed]

31. Bowen, M.; Edgar, D.F.; Hancock, B.; Haque, S.; Shah, R.; Buchanan, S.; Iliffe, S.; Maskell, S.; Pickett, J.; Taylor, J.P.; et al. The Prevalence of Visual Impairment in People with Dementia (the PrOVIDe Study): A Cross-Sectional Study of People Aged 60-89 Years with Dementia and Qualitative Exploration of Individual, Carer and Professional Perspectives; NIHR Journals Library: Southampton, UK, 2016.

32. Lindenberger, U.; Baltes, P.B. Sensory Functioning and Intelligence in Old-Age - a Strong Connection. Psychol. Aging 1994, 9, 339-355. [CrossRef] [PubMed] 
33. Tay, L.; Lim, W.S.; Chan, M.; Ye, R.J.; Chong, M.S. The Independent Role of Inflammation in Physical Frailty among Older Adults with Mild Cognitive Impairment and Mild-to-Moderate Alzheimer's Disease. J. Nutr. Health Aging 2016, 20, 288-299. [CrossRef] [PubMed]

34. Rovner, B.W.; Casten, R.J. Activity loss and depression in age-related macular degeneration. Am. J. Geriatr. Psychiatr. 2002, 10, 305-310. [CrossRef]

35. Lautenschlager, N.T.; Cox, K.L.; Flicker, L.; Foster, J.K.; van Bockxmeer, F.M.; Xiao, J.G.; Greenop, K.R.; Almeida, O.P. Effect of physical activity on cognitive function in older adults at risk for Alzheimer disease-A randomized trial. Jama J. Am. Med. Assoc. 2008, 300, 1027-1037. [CrossRef] [PubMed]

36. Auyeung, T.W.; Lee, J.S.; Kwok, T.; Woo, J. Physical frailty predicts future cognitive decline-A four-year prospective study in 2737 cognitively normal older adults. J. Nutr. Health Aging 2011, 15, 690-694. [CrossRef] [PubMed]

37. Malmstrom, T.K.; Morley, J.E. The frail brain. J. Am. Med. Dir. Assoc. 2013, 14, 453-455. [CrossRef] [PubMed]

38. Yu, R.; Morley, J.E.; Kwok, T.; Leung, J.; Cheung, O.; Woo, J. The Effects of Combinations of Cognitive Impairment and Pre-frailty on Adverse Outcomes from a Prospective Community-Based Cohort Study of Older Chinese People. Front. Med. 2018, 5, 50. [CrossRef] [PubMed]

39. World Health Organization. Integrated Care for Older People: Guidelines on Community-Level Interventions to Manage Declines in Intrinsic Capacity; Department of Ageing and Life Course: Geneva, Switzerland, 2017.

(C) 2019 by the authors. Licensee MDPI, Basel, Switzerland. This article is an open access article distributed under the terms and conditions of the Creative Commons Attribution (CC BY) license (http://creativecommons.org/licenses/by/4.0/). 